\title{
Effect of Antihypertensive Drugs on the "Intrinsic" Heart Rate
}

\author{
A. KÁLDOR,* M.D. ; P. JUVANCZ,† M.D.
}

Cummary : "Intrinsic" heart rate in man was measured by giving simultaneous atropine and propranolol and used to study the direct effect of antihypertensive drugs on the heart. Though the intrinsic and control heart rates decreased significantly following the administration of reserpine, there was no significant difference between high and low doses. No similar effects were observed with debrisoquine sulphate and methyldopa, though in high doses the latter produced a decrease which was of some statistical significance.

\section{Introduction}

Modern trends in studying the mechanisms of various kinds of hypertension and in introducing new and effective antihypertensive compounds have brought into prominence the detailed study of heart function in hypertension and during antihypertensive therapy. A practical study of isolated heart function, however, has been made only in animals, in which neural and humoral factors have been eliminated by surgical isolation of the heart. With the method of Jose (1966) a similar condition can be produced by counteracting both the sympathetic and parasympathetic stimuli with the simultaneous use of adequate doses of atropine and propranolol. This may prevent vagal and sympathetic stimuli altering the heart rate in man and dogs for about 20 minutes. Nevertheless, in healthy subjects an increase in heart rate may occur. This "intrinsic" heart rate (Jose, 1966) which is constant under various conditions in the same person, decreased with age as well as in various disorders, and increased in thyrotoxicosis (Frick, Heikkilä, and Kahanpää, 1967). Other workers examined the effect of physical training and found that intrinsic heart rate values in young subjects are lower after eight weeks' training (Sutton, Cole, Gunning, Hickie, and Seldon, 1967). It may be of theoretical and practical importance to know whether brady-

* Head of the Unit of Clinical Pharmacology, Second Department of Medicine, Medical University, Budapest, Hungary. t Research Assistant. cardia, in an individual patient, is due to neurohumoral influence or to a direct effect on the heart.

The effect of thiazide drugs on heart rate has not been established; our studies therefore were confined to three types of antihypertensive drugs ; the rauwolfia alkaloids, which themselves produce bradycardia (Cottier, 1967), the adrenergic neurone-blocking drug debrisoquine, which does not affect heart rate in the supine position even after prolonged administration-whereas in the prone patient the decrease may of ten reach 40\% (Gent and Bacon, 1967 ; Cranston, 1967)-and methyldopa, which may in some subjects produce definite bradycardia (Dollery and Harington, 1962 ; Bayliss and HarveySmith, 1962).

\section{Methods}

Twenty-eight patients were investigated after their informed consent had been obtained. Of these none had any cardiac disease, and those with hypertension had no signs of coronary insufficiency or of congestive heart failure. The basic intrinsic heart rate values and those following the administration of antihypertensive drugs were recorded after 10 to 15 minutes' bed rest at room temperature between 12 noon and 2 p.m. Heart rate was recorded by E.C.G. by use of the mean of three recordings at one-minute intervals. Atropine $0.04 \mathrm{mg}$. $/ \mathrm{kg}$. and propranolol $5 \mathrm{mg}$. were given intravenously and intrinsic heart rate values were recorded four, five, and six minutes later. The injection of the compounds lasted two minutes. The antihypertensive drugs were given alternately in two doses-the usual therapeutic dose and a higher dose close to the permissible maximal dose. After the basal values had been recorded the patients were given during the next 24 hours two 750-mg. doses of methyldopa, two 40-mg. doses of debrisoquine sulphate, or two $2 \cdot 5-\mathrm{mg}$. doses of reserpine. In the second study two $2,000-\mathrm{mg}$. doses of methyldopa, two 80 -mg. doses of debrisoquine sulphate, or two $0.75-\mathrm{mg}$. doses of reserpine were given. During the experiments no serious side-effects were found; some patients had temporary dryness

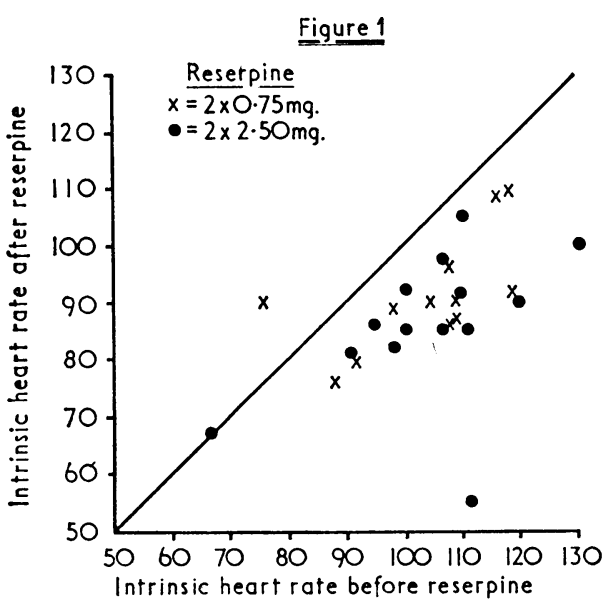

Fig. 1.-Effect of reserpine on intrinsic heart rate.

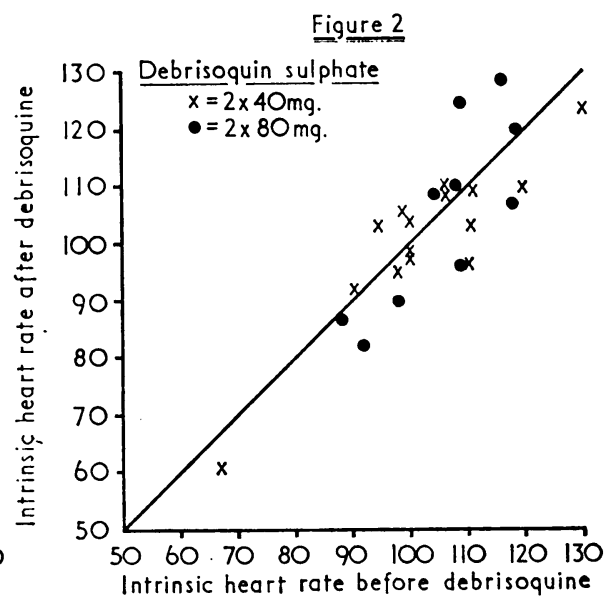

FIG. 2.-Effect of debrisoquine on intrinsic heart rate.

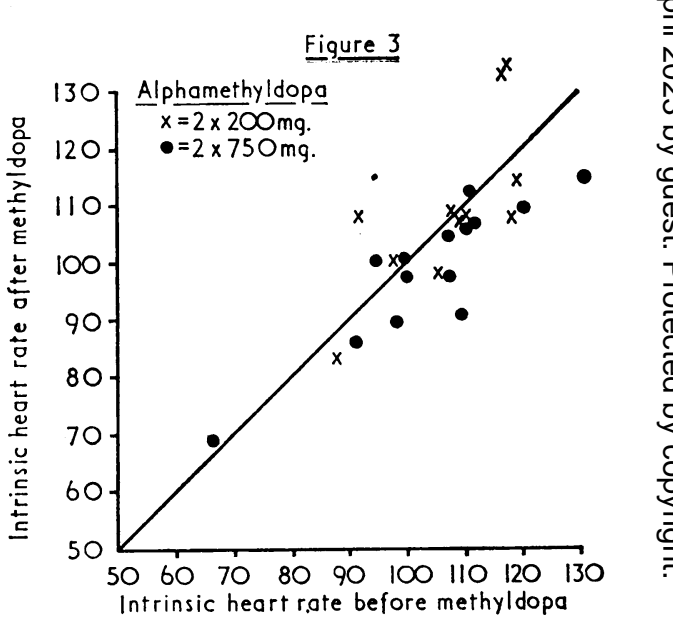

Fig. 3.-Effect of methyldopa on intrinsic heart rate. 
of the mouth and visual impairment, while others had drowsiness and depression. Orthostatic collapse occurred in one subject. Three persons refused to collaborate on the third day.

\section{Results and Discussion}

The results are summarized in the Table. The changes were computed, making each patient his own control, and those induced by the drugs were compared with those produced by atropine and propranolol. These differences in change of heart rate proved significant only for both doses of reserpine $(P<0.01)$ which caused a pronounced decrease in heart rate, whereas, for the other compounds, the only possibly significant finding was

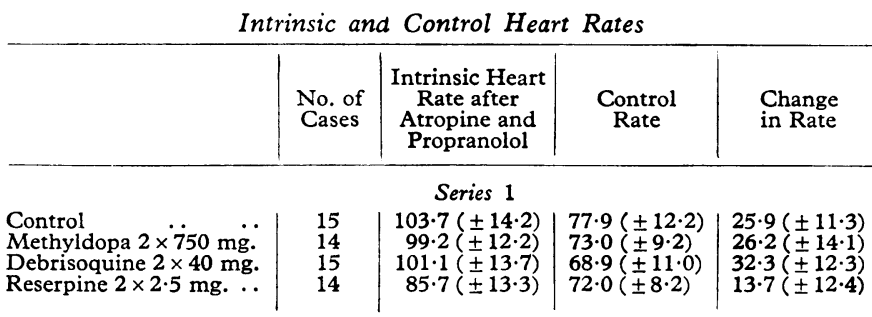

Series 2

\begin{tabular}{|c|c|c|c|c|}
\hline $\begin{array}{l}\text { Control } \\
\text { Methyldopa } 2 \times 2000 \mathrm{mg} \text {. } \\
\text { Debrisoquine } 2 \times 180 \mathrm{mg} \\
\text { Reserpine } 2 \times 0.75 \mathrm{mg}\end{array}$ & $\begin{array}{l}13 \\
12 \\
11 \\
12\end{array}$ & $\begin{array}{r}106 \cdot 5( \pm 10 \cdot 0) \\
109 \cdot 5( \pm 13 \cdot 8) \\
105 \cdot 9( \pm 15 \cdot 6) \\
91 \cdot 3( \pm 10 \cdot 0)\end{array}$ & $\begin{array}{l}77 \cdot 3( \pm 8 \cdot 3) \\
63 \cdot 8( \pm 11 \cdot 3) \\
69 \cdot 1( \pm 9 \cdot 6) \\
74 \cdot 4( \pm 8 \cdot 0)\end{array}$ & $\begin{array}{l}29 \cdot 2( \pm 12.5) \\
45 \cdot 8( \pm 19 \cdot 9) \\
36.8( \pm 19.0) \\
16.9( \pm 10.3)\end{array}$ \\
\hline
\end{tabular}

The standard deviation is given in parentheses after each mean.

a decrease in heart rate caused by a higher dose of methyldopa. The two $0.75-\mathrm{mg}$. doses of reserpine produced much the same effect as the two $2 \cdot 5-\mathrm{mg}$. doses. Contrary to expectation the bradycardia produced by reserpine, without giving atropine and propranolol, proved to be slight; in several cases the intrinsic heart rate even increased.

The individual values of the patients are given in Figs. 1, 2, and 3. The lines are drawn at $45^{\circ}$ to show the increase or decrease in intrinsic heart rate values compared with those in the self-controls.

As regards the mechanism of the decreasing effect of reserpine on the intrinsic heart rate we are compelled to speculate. The decrease of the catecholamine content of the sinus node has been suggested as a possibility by Dornhorst (Jose, 1966). It is well established, however, that the noradrenaline content of the heart decreases after giving adrenergic neurone-blocking agents and also after methyldopa, though perhaps by different mechanisms, because these compounds do not change the intrinsic heart rate (Figs. 2 and 3 ). In the normal subject reserpine has little effect on heart rate (see Table), yet it has a strong slowing effect on the impulse centre of the heart, which is apparent after total autonomic blockade. Hence reserpine may have a more complex action than is generally assumed and probably affects autonomic nerves as well as the heart itself.

\section{REFERENCES}

Bayliss, R. I. S., and Harvey-Smith, E. A. (1962). Lancet, 1, 763. Cottier, P. (1967). Schweizerische medizinische Wochenschrift, 97, 1768. Cranston, W. I. (1967). Practitioner, 198, 723.

Dollery, C. T., and Harington, M. (1962). Lancet, 1, 759.

Frick, M. H., Heikkilä, J., and Kahanpää, A. (1967). Acta Medica Scandinavica, 182, 621.

Gent, A. E., and Bacon, A. P. C. (1967). Practitioner, 198, 673.

Jose, A. D. (1966). American fournal of Cardiology, 18, 476.

Sutton, J. R., Cole, A., Gunning, J., Hickie, J. B., and Seldon, W. A. (1967). Lancet, 2, 1398.

\footnotetext{
* Associate Professor.

† Former Student, University of Washington School of Medicine, Washington 98105 .

Department of Orthopaedics, University of Washington School of Medicine, Washington 98105 .
}

colleagues of its value, primarily because of the difficulty they experienced in demonstrating the jerk, alternative methods of eliciting a tendon reflex mediated by the fifth lumbar root were sought. The purpose of the present paper is to describe these methods, which have also stood the test of time, and to draw attention to their distinct worth in the examination of the patient with lumbar intervertebral disc disorder.

\section{Deep Tendon Reflexes Associated with Extensor Apparatus of the Great Toe}

\section{Great-toe Jerk}

The great-toe jerk, as described by Ransome, is elicited from the hallux with a tendon hammer by striking an index finger which depresses the digit so as to put slight "elastic" stretch on the tendons of the extensors hallucis longus and brevis. The foot is placed in plantar flexion and slight inversion. The reflex contraction is felt rather than seen, though the latter may be the case when the response is exaggerated. In this context Ransome suggested an alternative name for the reflex, the 